\title{
Topoclimatic modeling for minimum temperature prediction at a regional scale in the Central Valley of Chile*
}

\author{
F Santibáñez $^{1 *}$, L Morales $^{1}$, J de la Fuente ${ }^{1}$, P Cellier $^{2}$, A Huete $^{3}$ \\ 'Facultad de Ciencias Agrarias y Forestales, Universidad de Chile, Santa Rosa 11.315, Casilla 1004, Santiago, Chile; \\ 2 Unité de recherches en bioclimatologie, Inra, 78850 Thiverval-Grignon, France; \\ ${ }^{3}$ Dept of Soil and Water Science, University of Arizona, Tucson, AZ 85721, USA
}

(Received 20 October 1996; revised 15 May 1997; accepted 14 August 1997))

\begin{abstract}
Summary - Spring frost may strongly affect fruit production in the Central Valley of Chile. Minimum temperatures are spatially variable owing to topography and soil conditions. A methodology for forecasting minimum temperature at a regional scale in the Central Valley of Chile, integrating spatial variability of temperature under radiative frost conditions, has been developed. It uses simultaneously a model for forecasting minimum temperatures at a reference station using air temperature and humidity measured at $6 \mathrm{pm}$, and topoclimatic models, based on satellite infra-red imagery (NOAA/AVHRR) and a digital elevation model, to extend the prediction at a regional scale. The methodological developments were integrated in a geographic information system for georeferencing of a meteorological station with satellite imagery and modeled output. This approach proved to be a useful tool for short range (12 h) minimum temperature prediction by generating thermal images over the Central Valley of Chile. It may also be used as a tool for frost risk assessment, in order to adapt production to local climatological conditions.
\end{abstract}

spring frost / infrared imagery / satellite / digital elevation model / minimum temperature prediction

Résumé - Une méthode de prévision des températures minimales à l'échelle régionale dans la vallée centrale du Chili. Les gelées de printemps sont un facteur limitant important pour l'arboriculture chilienne dans la vallée centrale du Chili. Les températures minimales présentent une forte variabilité, en raison de la topographie et de l'occupation $\mathrm{du}$ sol. Cette étude présente une méthode de prévision des températures minimales à l'échelle régionale, intégrant la variabilité spatiale des températures en conditions de gelées de printemps. Elle utilise à la fois un modèle local de prévision de la température minimale utilisant la température et l'humidité de l'air mesurées sur une station météorologique à $18 \mathrm{~h}$ TU, et un modèle topoclimatique basé sur l'utilisation de thermographies infrarouge (satellite NOAA/AVHRR) et d'un modèle numérique de terrain, pour étendre la prévision à l'échelle régionale. Ces modèles ont été intégrés dans un système d'information géographique pour la géoréférenciation des stations météorologiques de référence par rapport aux images satellitaires, et les sorties du modèle. Cette approche permet de générer des images de températures minimales prédites avec $12 \mathrm{~h}$ d'avance, sur l'ensemble de la vallée centrale du Chili, avec une précision voisine du degré Celsius. Elle permet également de faire un zonage des risques de gel pour une meilleure adaptation des cultures aux conditions climatiques locales.

gelée de printemps / thermographie infrarouge / satellite / modèle numérique de terrain / prévision de température minimale

\footnotetext{
* Research financed by project 1940266 and ECOS Program (Conicyt-Fondecyt, Chile)

* Correspondence and reprints

Tél: (56) 2678 5733; fax: (56) 2678 5700; e-mail: fsantiba@abello.dic.uchile.cl
} 


\section{INTRODUCTION}

Significant losses in agricultural production may result from frost, more especially at the farm and regional scale. In the Central Valley of Chile (fig 1) more than one million hectares may be affected by strong spring frosts every year. Frost regime is mainly radiative. The most affected crops are temperate and subtropical fruits, vegetables, horticultural crops and grapes. In several years, frost damage has reached critical levels. Analyzing meteorological data series confirms that, every 10 or 12 years, late extensive frosts (SeptemberOctober) cause critical economic effects. The last critical frost was in October 1991. It caused serious damages to wine and table grapes, resulting in considerable losses in production.

In areas with sufficient climatological information, the risk associated with frost may be quantified. By using this information together with a crop model and a climatic grid over the study area, estimates have been made of the economic costs of frosts for Chilean agriculture (Santibáñez and Merlet, 1987). They showed that direct losses due to frost are ranging between 25 millions $\$$ US in normal years and 80 in critical years. Whatever strategy is used to reduce the impact of frosts on agriculture, a reduction of $5 \%$ in economic losses could generate a return of up to 10 million dollars a year, just as a result of reducing direct losses. Indirect losses associated with wasted energy, chemical products, fertilizers and salaries yield approximatively the same amount as the direct losses. A frost warning system could therefore bring the potential return up to 20 million dollars a year. Moreover, a detailed system for evaluating frost risk would contribute to limiting the impact of frost, either by determining best areas for planting or by helping to choose plant varieties best adapted to the frost dates and intensity. At the same time, this would aid in the design of control strategies accounting for the strong spatial variability of this phenomena.

Up to now, no detailed evaluation of the spatial variation of frost risk has been made for Chile. At the level of individual growers, no warning system allowing identification of the risk exists. Minimum temperatures are presently predicted using formulae developed outside the country (Bagdonas et al, 1978). These formulae work at synoptic scale, and hence cannot take into consideration local circulations that often condition the spatial variability of minimum temperatures. They are generally designed for flat terrains in which radiative cooling explains most of the temperature decrease during the night. Over uneven terrains, such as in the central zone of Chile, local processes may decrease or increase frost probability. However, accounting for the local effects associated with topography or soil types is not straightforward. Mechanistic modeling is complex (Kaimal and Finnigan, 1983; Avissar and Mahrer, 1988) and not yet adapted to operational use. Direct measurement are often difficult to extrapolate and are unable to account for temperature heterogeneity at the regional scale (Bootsma, 1975; Laughlin and Kalma, 1987). Nowadays, thermal infrared imagery is certainly

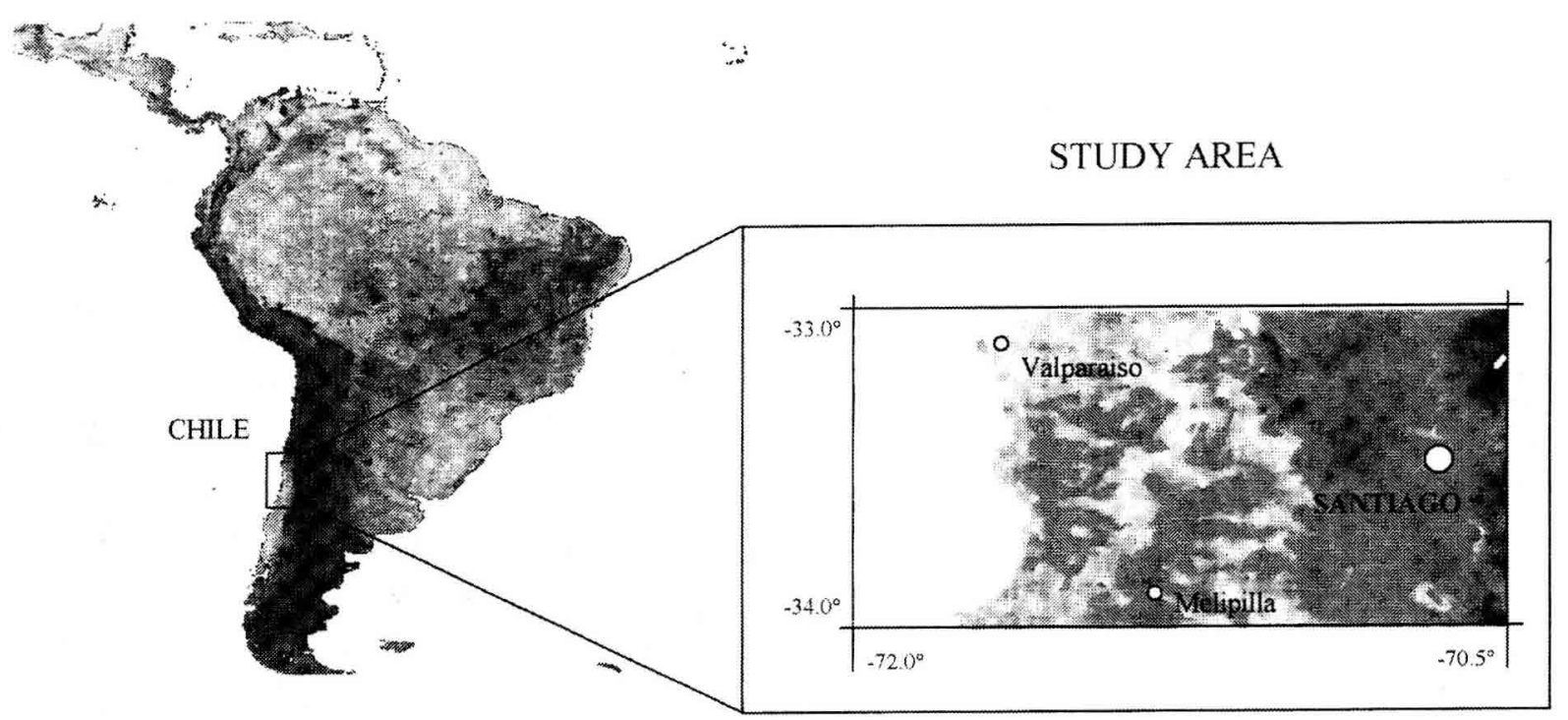

SOUTH AMERICA

Fig 1. Map of experimental area. 
the best way to investigate minimum temperature distribution under radiative frost conditions (Antonioletti, 1993).

The objective of this work is to develop a regional system for frost alerts. This is performed through integration of a local frost forecasting model based on classical meteorological data, and of a topoclimatic model using satellite thermal infrared images. This study focuses on an area located within the $\mathrm{V}$ region of Chile, which includes the Metropolitan area of Santiago (fig 1).

\section{MATERIALS AND METHODS}

\section{Empirical formulae to forecast minimum temperature}

Several empirical formulae to forecast minimum temperature (Young, 1920; Allen, 1957; Wong, 1982) were evaluated in the Central Valley of Chile.

None of these formulae predicted minimum temperature within an acceptable margin of error. Considering this, we developed a new formula using our set of statistical data, including temperature and relative humidity on an hourly basis, and cloudiness observed three times a day. These data were obtained from three automatic meteorological stations (Campbell CR 10) installed in the study area for a period of 2 years. Additionally we obtained long-term daily climatic data from five conventional meteorological stations, distributed within an area of 100 by 100 $\mathrm{km}$.

The best fit was provided by the following equation (fig 2):

$$
\begin{gathered}
T_{\mathrm{f}}=0.461593\left(T_{\mathrm{d}}+T_{\mathrm{w}}\right)-3.74173+(0.125 * n * 1.8) \\
r^{2}: 0.6488 \\
\text { RMSE: } 2.0^{\circ} \mathrm{C}
\end{gathered}
$$

where $T_{\mathrm{f}}$ is the forecasted temperature; $T_{\mathrm{d}}$ is the air temperature at $20 \mathrm{~h} \mathrm{LST} \mathrm{(previous} \mathrm{day);} \mathrm{T}_{w}$ is the wet bulb temperature at the same time; and $n$ is the forecasted cloudiness for the next day, at the time of minimum temperature.

Figure 2 shows observed and predicted minimum temperature in Santiago (Chile), using the proposed formula. The forecasted minimum temperature is the main input of the topoclimatic model to optimize the prognosis at a regional scale.

\section{Estimation of surface temperature from satellite infrared images}

NOAA satellite (D, F, G and H) imagery retrieved and processed by the Space studies Center of the University of Chile in Santiago, was used to estimate the spatial distribution of land surface temperature, with $1 \mathrm{~km}$ resolution. The temperature of a given channel is interpreted as apparent temperature or brightness temperature, which is different from the actual surface temperatures, due to surface emissivity differences. Using channels 4 and 5, a split-window surface temperature algorithm was used to separate emissivity variance associated with the surface condition from that due to atmospheric (water vapor) effects (Sobrino and Caselles, 1991; Coll et al, 1992)

$$
T_{\mathrm{s}}=T_{4}+A\left(T_{4}-T_{5}\right)+B
$$

where $T_{4}$ and $T_{5}$ are the brightness temperatures given respectively by channels 4 and 5 , and $T_{\mathrm{s}}$ is the corrected surface temperature with an estimated error varying within the range $8-11^{\circ} \mathrm{C}$, depending on atmospheric conditions. Table I summarizes the $A$ and $B$ coefficients, as reported by Sobrino and Caselles (1991) and Coll et al (1992). Spatial resolution of original images was improved to $250 \times 250 \mathrm{~m}$ using a resampling method based on a quadratic algorithm of interpolation.

Table I. Coefficient values of $A$ and $B$ for equation [2] for two atmospheric conditions (seasons) and three types of surface conditions.

\begin{tabular}{lcccccc}
\hline & \multicolumn{2}{c}{ Ocean } & \multicolumn{2}{c}{ Vegetation } & \multicolumn{2}{c}{ Desert } \\
\hline & $A$ & $B$ & $A$ & $B$ & $A$ & $B$ \\
\hline Winter & 1.62 & 0.07 & 1.69 & 1.24 & 1.79 & 3.24 \\
Summer & 2.25 & 0.21 & 2.34 & 0.96 & 2.49 & 2.48 \\
\hline
\end{tabular}

\section{Topoclimatic modeling of surface temperature}

\section{General approach}

The spatial variations of frost are often dramatic over mountainous topography. Topography regulates night air circulation in such a way that strong temperature differences may be observed at small scale (Bootsma, 1975; Laughlin and Kalma, 1987). For example, Durand (1978) observed temperature differences larger than $5^{\circ}$ over a distance of $250 \mathrm{~m}$ and differences in elevation of $15 \mathrm{~m}$. Other variations may be due to soil type, thermal inversion, or advection (Cellier, 1993). These differences are linked to physical processes that are the same for every night, with variable intensity, according to the cloud and wind conditions. Then, the thermal patterns are likely to be similar for different nights, provided the processes that drive nocturnal cooling are the same, ie, strong radiative deficit. This allows for the development of models based on algorithms that relate entire areas with a thermal pattern to a point reference that coincides with a meteorological station. To elaborate a spatial model it is possible to use a geo-referenced grid that allows for resampling thermal satellite images. In this grid, temperature, elevation, and other attributes can be known for each 


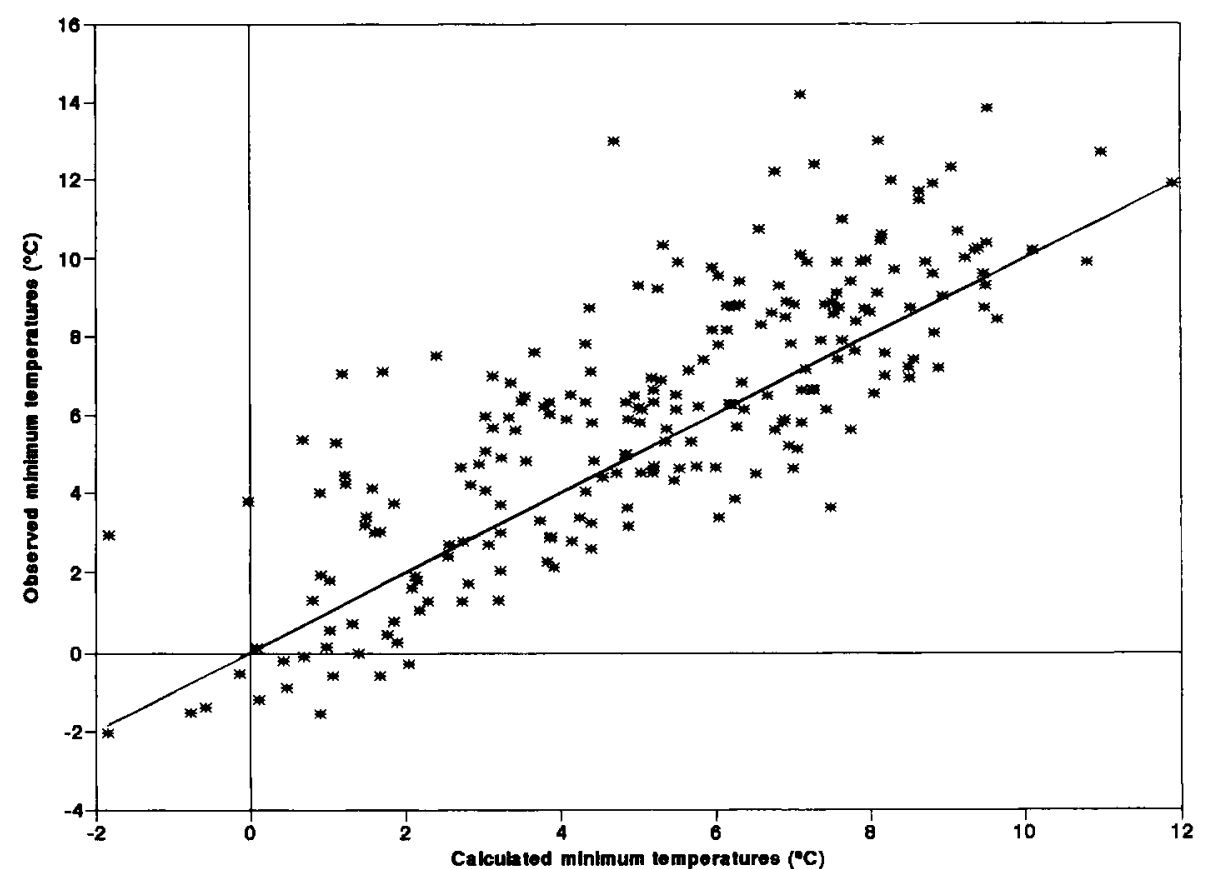

Fig 2. Comparison between observed $(1.5 \mathrm{~m})$ and calculated minimum temperatures. pixel. Based on this type of spatial information, two approaches were developed to achieve a spatial distribution of frost forecasts and risk assessment. The first is based on satellite infrared imagery, and the second on a digital elevation model (DEM).

\section{Modeling of spatial variations of surface temperature}

A software was created for analyzing thermal spatial configurations registered during a satellite passing. It was developed in the frame of a geographic information system (IDRISI). Based on a set of 40 satellite images corresponding to frost, the software analyzes, pixel by pixel, the temporal series of image, generating a complete diagnosis of the behavior of each pixel in different situations corresponding to different nights. Each row in the input matrix is treated as a time series. This software allows one to perform a statistical analysis of the differences of one pixel and a reference pixel within the images. The reference pixel can also be the average calculated over the entire image. The software carries out linear regressions between any pixel and a reference pixel, generating a file containing the $A$ and $B$ coefficients, and a IDRISI image of the Pearson coefficient $(r)$.

Five conventional meteorological stations were selected (table II) as references. Figure 3 shows the spatial distribution of the Pearson coefficient calculated from the temperatures of the pixel corresponding to each meteorological station, and every pixel of the thermal images for our set of satellite images. These pictures provide information on the representative areas of each station, ie, the area of potential validity of a linear model in relating any pixel with a station.
This indicates that starting with a known temperature in a meteorological station, it is possible to determine the temperature for all the other points within the representative area, corresponding to this meteorological station.

This is accomplished with the following empirical relationship:

$$
t(i)=a(i)+b(i) * T_{r}
$$

where $t(i)$ is the calculated temperature of the $i$-pixel, $a(i)$ and $b(i)$ are the parameters of the linear equation relating the temperature of the $i$-pixel to the temperature of the reference station, $T_{r}$.

\section{DEM-based model}

By using a digital elevation model, built at a resolution of $250 \times 250 \mathrm{~m}$, the same as the NOAA improved resolution, we produced maps of elevation, slope, azimuth and distance to the ocean. Any other type of information relative to the pixel, such as vegetation index, or its surroundings can also be taken into

Table II. Meteorological stations used in model development.

\begin{tabular}{lccc}
\hline $\begin{array}{l}\text { Meteorological } \\
\text { station }\end{array}$ & Latitude & Longitude & $\begin{array}{c}\text { Elevation } \\
(m)\end{array}$ \\
\hline Jardin Botánico & $33^{\circ} 03^{\prime}$ & $71^{\circ} 29^{\prime}$ & 50 \\
Casablanca & $33^{\circ} 19^{\prime}$ & $71^{\circ} 25^{\prime}$ & 230 \\
Cerro Calan & $33^{\circ} 23^{\prime}$ & $70^{\circ} 32^{\prime}$ & 860 \\
Antumapu & $33^{\circ} 34^{\prime}$ & $70^{\circ} 38^{\prime}$ & 605 \\
Melipilla & $33^{\circ} 42^{\prime}$ & $71^{\circ} 14^{\prime}$ & 169 \\
\hline
\end{tabular}


JARD IN B OTANICO

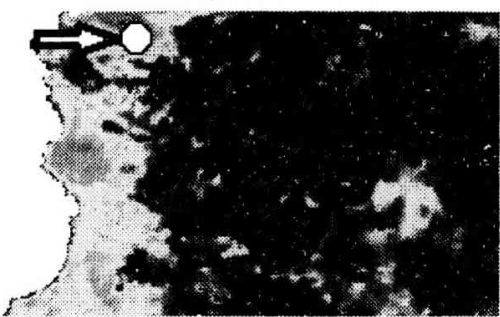

ANTUMAPU

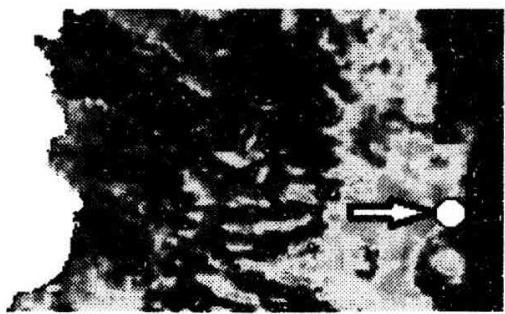

CASABLANCA

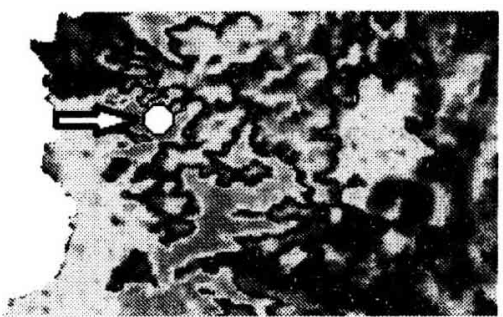

MELIPILLA

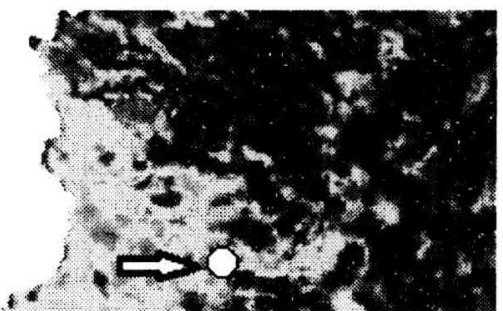

CERRO CALAN
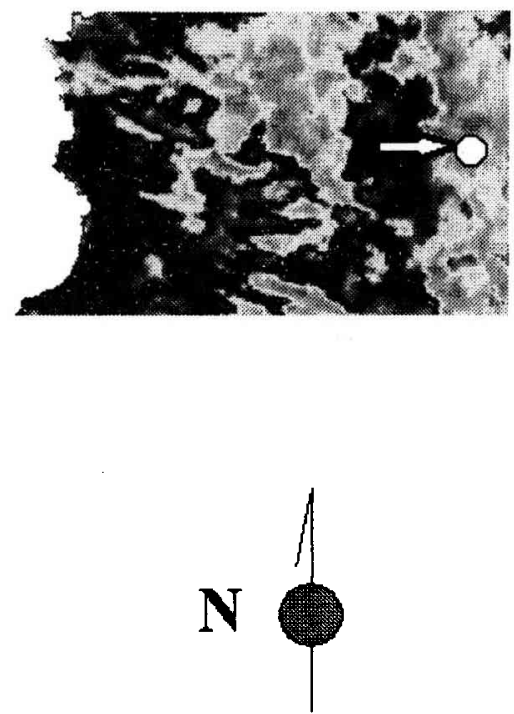

Fig 3. Representativeness of each reference meteorological station. Light-colored zones represent the areas of high correlation coefficient in relation to corresponding meteorological station.

account. A model, called MULTIR, produces a multiple regression among spatial data sets in IDRISI format, between observed temperature, temperature calculated by eq [3], and the physical characteristics mentioned above. Any given variable can be chosen as the independent variable influencing minimum temperature.

The regression model can be expressed as follows:

$$
T(i)=a_{0}+\sum_{k=1}^{k} b_{0}(K) X_{k}(i)+C_{0} t(i)+e
$$

where $a_{\theta}, b_{0}(K)$ and $C_{0}$ are the coefficients calculated by the multiple linear regression between various images/parameters and $e$ represents the error associated with the fitting process. $X_{1}(i)$ is elevation, $X_{2}(i)$ and $X_{3}(i)$ are the slope and azimuth, and $X_{4}(i)$ is the distance to the seaside; $t(i)$ is the temperature obtained from eq [3] and $i$ represents a selected pixel from the images. Table III summarizes the coefficients derived from eq [4].
The multiple regression models for each pixel corrects the linear eq [3] in order to improve the regional thermal images.

\section{RESULTS}

Coupling conventional forecasting methods and topoclimatic models, we generated a system for regional forecasting of minimum temperatures in the central zone of Chile. We tested the validity of these approaches with various computer simulations, designed to generate thermal images. In a first step, we reproduced the entire satellite images using as input only the average regional temperature as a reference. This regional temperature value was calculated as a mean value of the available meteorological stations. In this case, we

Table III. Coefficients of eq [4] estimated over five satellite infrared images (each column corresponds to one image).

\begin{tabular}{lrrrrr}
\hline & $T 495231$ & $T 495230$ & $T 495229$ & $T 495189$ & $T 495134$ \\
\hline$a_{0}$ & -0.505 & -1.462 & -0.257 & 0.245 & 2.045 \\
$b_{0}(1)(\times 10-3)$ & -1.521 & 1.750 & -0.953 & 0.055 & 1.158 \\
$b_{0}(2)$ & 0.842 & 0.291 & 0.483 & -0.226 & -1.676 \\
$b_{0}(3)(\times 10-4)$ & 9.48 & -5.88 & -4.88 & -0.88 & 11.57 \\
$b_{0}(4)$ & 4.05 & 4.72 & 1.20 & 3.56 & -0.57 \\
$c_{0}$ & 0.933 & 1.091 & 0.878 & 1.076 & 0.857 \\
$r$ & 0.88 & 0.90 & 0.94 & 0.91 & 0.84 \\
Error $\left({ }^{\circ} \mathrm{C}\right)$ & 1.47 & 1.22 & 0.83 & 1.17 & 1.39 \\
\hline
\end{tabular}


used five stations. For each of them, we estimated the minimum temperature by means of an empirical forecasting method (eq [1]). To create a simulated regional image, the temperature at each pixel is calculated by eq [3] using the regional temperature as reference. To automatize this procedure, we created a software called SIM (image simulator for regional temperature). The model can also generate a thermal image separately for each representative area of individual meteorological stations. This allows us to use local calibrated forecasting methods. In this case, the regional image is obtained by associating partial images of each area. This procedure is longer but improves the simulated regional image. This procedure is automated by using the SIF software (simulator for regional temperature from multiple references). This software produces a calculated image from the images generated by SIM as well as from DEM. Then images provided by SIF can be used by MULTIR.

Figure 4a shows the image obtained from channel 4 of the NOAA satellite for July 23 1988, in which the different thermal patterns can be observed, represented by colors associated with the range of temperature values. Figure $4 b$ shows an image produced by the SIF model for the same day. The input values for the SIF model are: the representative area of each meteorological station, elevation map, aspect map, distance from the coast, and an image generated by the SIM program for the same conditions. In order to generate the SIM image, temperature values were required from the five meteorological stations. An example of simulated thermal imagery with the MULTIR model is shown in figure 5. The correlation coefficient between the original satellite image (fig 4a) and that generated by the SIM model was 0.57 . The correlation coefficient between the original image and that generated by the SIF model (fig 4b) was 0.88 and that with MULTIR (fig 5b) 0.94. It is important to note that this simple model is capable of quantitatively describing the spatial pattern of surface temperatures from point source references. With an average error of 0.83 to $1.47^{\circ} \mathrm{C}$ (see table III).

Starting from this model, images were simulated corresponding to historical extremes of minimal temperatures from the stations that were used. This procedure generated a series of images that were analyzed pixel by pixel, in order to find the probability of frost occurrence. The results are shown in figure 6 , where the probability of a negative temperature occurence in a $i$-pixel can be seen when a negative temperature occurs in the related meteorological station. This was interpreted as a map of frost risk showing areas at greater risk of frost owing to topography and local environment. (a)

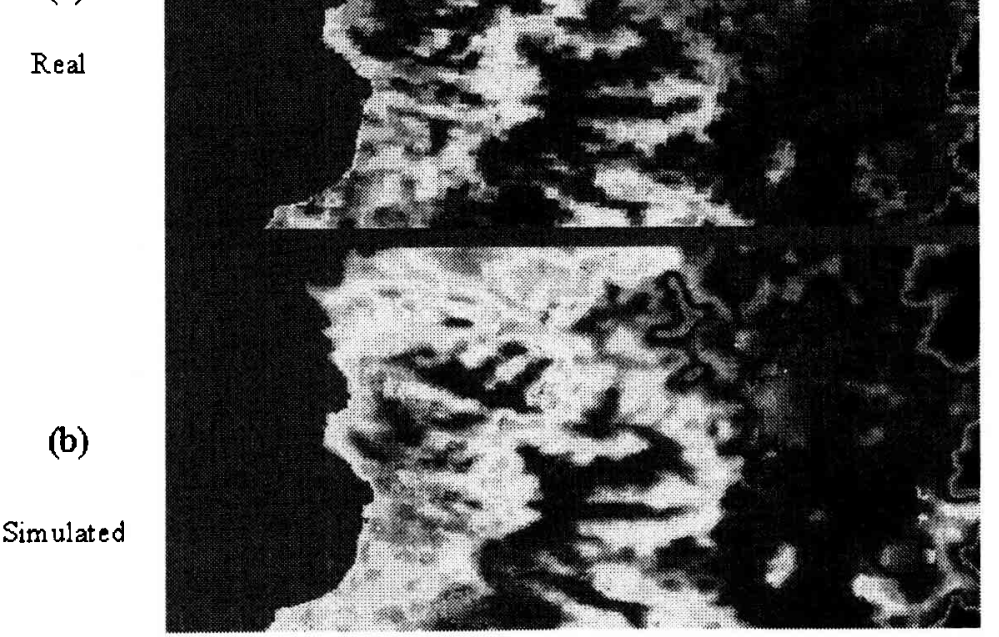

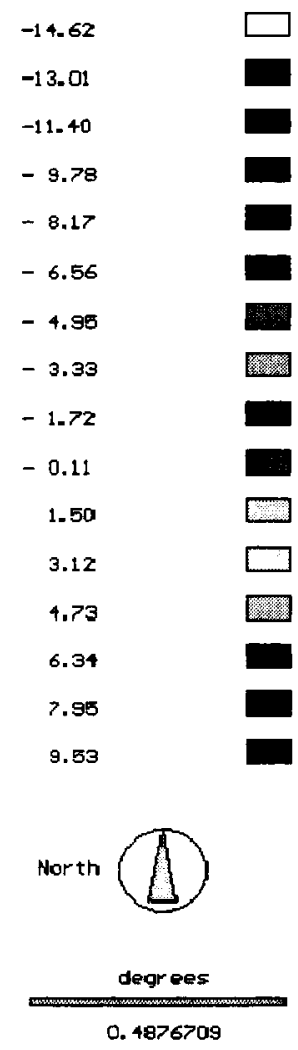

Fig 4. Map of surface temperature $\left({ }^{\circ} \mathrm{C}\right.$ ) given by satellite imagery (a) and SIF model (b) for 23 July 1988. 
(a)

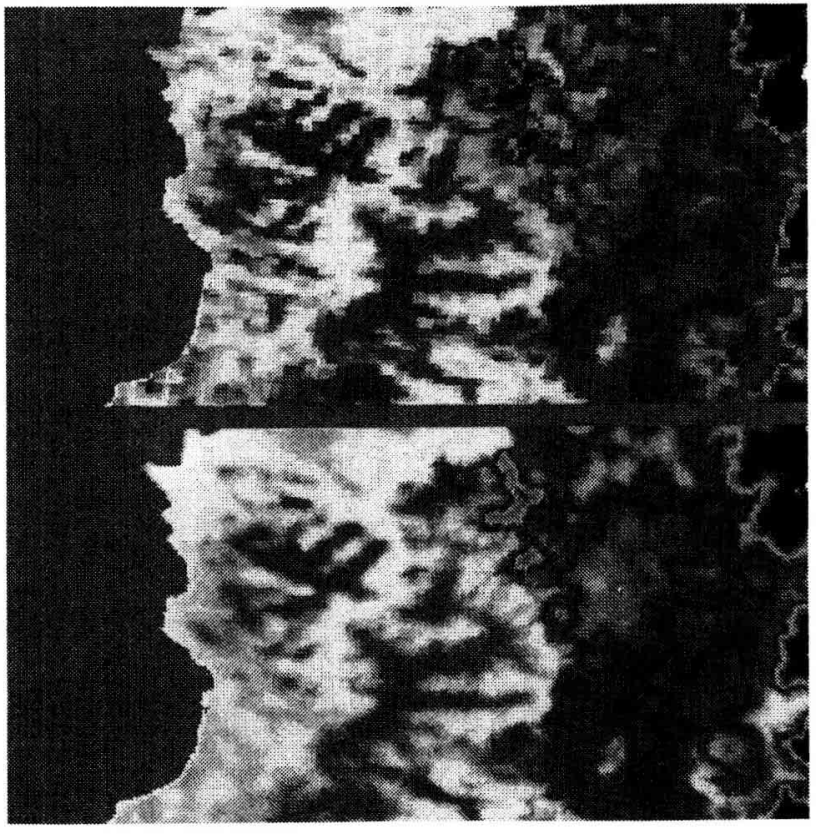

$-14.62$

$-13.01$

$-11.40$

$-9.78$

$-8.17$

$-6.56$

$-4.95$

- 3.33

$-1.72$

$-0.11$

1.50

3.12

4.73

6.34

7.95

9.53

Simulated

(b)
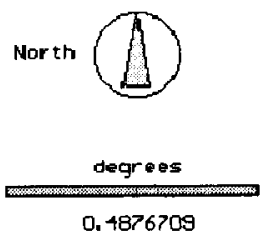

Fig 5. Map of surface temperature $\left({ }^{\circ} \mathrm{C}\right.$ ) given by satellite imagery (a) and MULTIR model (b) for 23 July 1988.

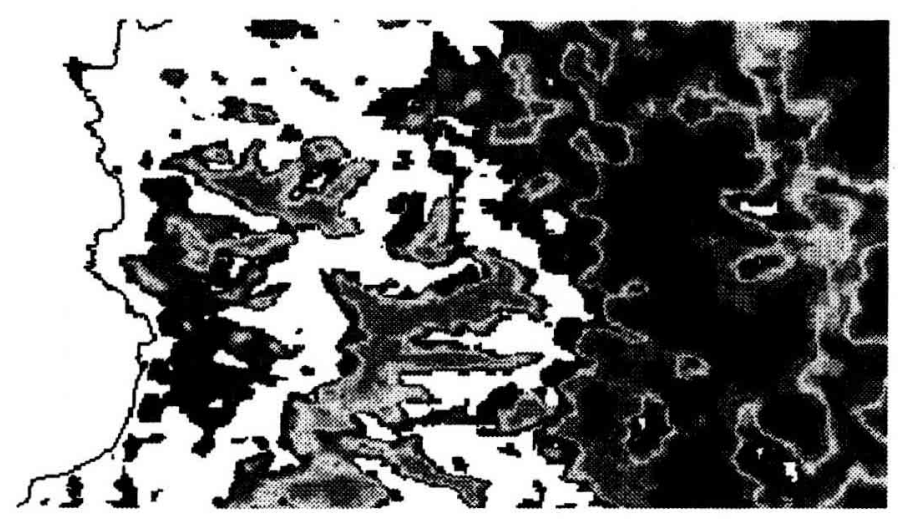

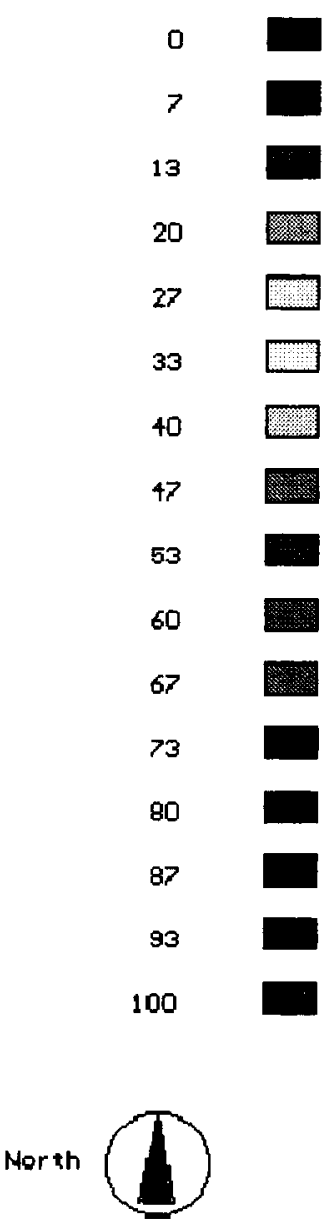

Fig 6. Map of different frost probability in $\%$ using as reference days of frost occurrence in Santiago airport. 


\section{CONCLUSIONS}

The linkage of point-based (meteorological station) temperature forecasting methods with topoclimatic models allows for regionalizing a frost risk forecasting system. By means of topoclimatic models we can demostrate the high correlation between surface temperature patterns and topography. The temperature forecasting method has predicted temperatures with a good accuracy. The NOAA thermal images have shown themselves to be a useful tool for studying the climatology of minimum temperature, as related to local topographic features. This is a helpful method establishing for representative areas of individual meteorological stations.

Acknowledgment: We would like to express our acknowledgment to Ecos Program (France-Chile cooperation) and FONDECYT (Chile) which provided financial support to this investigation (Project: 1940266) and STD3-Contract TS3CT93-239 of the European Commission.

\section{REFERENCES}

Allen CC (1957) A simplified equation for minimum temperature prediction. Monthly Weather Rev 85, $119-120$

Antonioletti R (1993) Apport de la télédétection à la délimitation des zones gélives. In: Le gel en agriculture, (C Riou, ed), Séminaire, Inra Commission d'agrométéorologie, Paris, 21-22/1 1/1989, 201-209

Avissar R, Mahrer Y (1988) Mapping frost sensitive areas with a three-dimensional local-scale numeri- cal model. Part I. Physical and numerical aspects. $J$ Appl Meteorol 27, 400-413

Bagdonas A, Georg JC, Gerber JF (1978) Techniques of frost prediction and methods of frost and cold protection. WMO $\mathrm{N}^{\circ} 487$, technical note No 157 , $160 \mathrm{p}$

Bootsma A (1975) Estimating minimum temperature and climatological freeze risk in hilly terrain. Agric Meteorol 16, 425-433

Cellier P (1993) Mécanismes du refroidissement nocturne. Application à la prévision des gelées de printemps. In: Le gel en agriculture (C Riou, ed), Séminaire, Inra Commission d'agrométéorologie, Paris, 21-22/11/1989, 145-164

Coll C, Sobrino J, Caselles V (1992) Parametrización de la absorción del vapor de agua atmosférico en el infrarrojo térmico. Desarrollo de un algoritmo de split-window para la superficie terrestre. Actas de la IV Reunión Científica de la Asociación española de Teledetección

Durand R (1978) Comment déterminer une situation gélive ? In: CR Journées nationales d'information "Lutte contre les gelées » (Insuflec, ed), Angers, $29-49$

Kaimal JC, Finnigan JJ (1993) Atmospheric Boundary Layer Flows. Their Structure and Measurement. Oxford Univ Press, New York, $289 \mathrm{p}$

Laughlin GP, Kalma JD, 1987. Frost hazard assessment from local weather and terrain data. Agric For Meteorol 40, 1-16

Santibáñez F, Merlet H (1987) Regímenes de heladas en la zona Central de Chile. Aconex 16, 20-27

Sobrino J, Caselles V (1991) A methodology for obtaining the crop temperature from NOAA-9 AV HRR data. Int J Remote Sensing 12, 246 I-2475

Wong JY (1982) The gromer's weather guide for farming practices. Milian Information Service, Ive Sean Jose, CA, 66 p

Young FD (1920) Forecasting minimum temperatures in Oregon and California. Monthly Weather Rev 16, Supplement, 53-60 